\title{
COMPARISON OF EFFICACY AND SAFETY OF ORMELOXIFENE AND CYCLICAL PROGESTERONE (NORETHISTERONE) IN OVULATORY ABNORMAL UTERINE BLEEDING
}

\author{
DIVYA VARDAINI ${ }^{1}$, RAKESH MISHRA ${ }^{2}$, RASHMI RANJAN ${ }^{3}$, SWAPNALI R BORADE $^{4}$
}

${ }^{1}$ Department of Pharmacology, World College of Medical Sciences and Research, Jhajjar, Haryana, India. ${ }^{2}$ Department of FMT, Veer Chandra Singh Garhwali Government Institute of Medical Science and Research, Srinagar, Uttarakhand, India. ${ }^{3}$ Department of PSM, World College of Medical Sciences and Research, Jhajjar, Haryana. Email: dvardaini@gmail.com

Received: 24 July 2020, Revised and Accepted: 05 October 2020

ABSTRACT

Objective: The objective of the study was to determine the efficacy and safety of ormeloxifene (ORM) versus norethisterone in controlling ovulatory abnormal uterine bleeding (AUB-O).

Methods: A prospective randomized comparative study of total 100 females of reproductive age in the age group 25-45 years with AUB-0. Patients were randomly divided in two groups of 50 each.

Results: ORM is more effective in reducing blood loss leading to improvement in mean hemoglobin and it also showed a higher ability to reduce endometrial thickness.

Conclusion: While both ORM and norethisterone are very effective drugs for AUB-O, ORM is safer, more cost-effective, non-steroidal, and nonhormonal drug with appropriate dosage and delivers better results for medical management of AUB-O. Therefore, ORM can be considered as the preferred drug in the management of AUB-O.

Keywords: Abnormal uterine bleeding, Ovulatory dysfunction, Endometrial hyperplasia, Ormeloxifene, Norethisterone, Selective estrogen receptor modulator, Hemoglobin, Heavy menstrual bleeding, Central nervous system.

(C) 2020 The Authors. Published by Innovare Academic Sciences Pvt Ltd. This is an open access article under the CC BY license (http://creativecommons. org/licenses/by/4. 0/) DOI: http://dx.doi.org/10.22159/ajpcr.2020.v13i11.39216

\section{INTRODUCTION}

Menstrual disorders are the second most common gynecological conditions in hospital referrals. Abnormal uterine bleeding (AUB) includes all patterns of uterine bleeding that does not follow the normal menstrual pattern. AUB is an abnormality in volume, regularity, and/ or timing lasting for 6 months. According to the classification given by FIGO (International Federation of Gynecology and Obstetrics), AUB-O is categorized in FIGO- system 2 [1]. It includes conditions such as polyp, adenomyosis, leiomyoma, malignancy, hyperplasia, coagulopathy, ovulatory dysfunction, endometrial, iatrogenic, and those not yet classified. AUB-O can affect women from adolescence to perimenopausal years.

More and more women are looking forward for better and more convenient medical treatment. Even though there are a number of treatments available, a reliable drug for the management of AUB should meet requirements such as effectiveness, convenience, costeffectiveness with minimal side effects, and long safety margin.

Approaches to medical management have been hindered by highly variable and non-evidence-based prescribing habits and lack of understanding of mechanisms causing AUB-O. The ideal treatment for AUB should be a designer drug which can block the action of estrogen on the endometrium; it is beneficial actions on the other tissues. Selective estrogen receptor modulators (SERMs) are one such class of drugs which have both agonistic and antagonistic actions on estrogen receptors [2]. They have varied tissue response which behaves as an estrogen antagonist in uterus and breast, being mildly agonist action on vagina, bone mineral density, central nervous system, and serum lipids, making it the perfect SERM for AUB-O. The current study was undertaken to the hypothesis that ormeloxifene (ORM) is superior to cyclical progesterone therapy in the treatment of pre-menopausal AUB-O [3].

\section{MATERIALS}

Place

The study was carried at the Department of Obstetrics and Gynaecology of Mata Chanan Devi Hospital, Janakpuri, New Delhi.

Study design

A prospective randomized comparative study.

\section{Sample size}

A total of 100 female patients were enrolled in this study. It was calculated keeping in view at the most $5 \%$ risk, with a minimum $80 \%$ power and 5\% significance level.

Timeframe

March 2019 to December 2019

\section{Inclusion criteria}

Females in the reproductive age group, 25-45 years with AUB-0, were in the study.

\section{Exclusion criteria}

Women with

- Uterine pathology, for example, uterine polyp, leiomyoma, adenomyosis, and iatrogenic endometrial disorder

- Pelvic pathology and malignancies

- $\quad$ Systemic disorders

- Any history of thrombosis, bleeding disorder

- Severe anemia (<7 g)

- Pregnancy, abortion, ectopic, increased bleeding due to IUCDS

- Consistent use of oral contraceptive

- Hypersensitivity to the drug

- History of breast malignancy 
- Suspected adenomyosis

- Current genital infection.

\section{Methodology}

The study was conducted after due approval of the Ethical Committee, Mata Chanan Devi Hospital, New Delhi. Patients were randomly divided in two groups of 50 each after taking informed consent from each patient who met the inclusion criteria. A thorough general and systemic examination was conducted before the study.

Patients enrolled in Group A received Tab ORM $60 \mathrm{mg}$ twice a week, with a minimum gap of 3 days for 3 months. Likewise, patients enrolled in Group B received progesterone in the form of tablet $5 \mathrm{mg}$ norethisterone twice a day for 21 days for 3 months starting from day 5 of the menstrual cycle. Hemoglobin (Hb) g\% was evaluated and TVS was repeated for endometrial thickness (ET) in the proliferative phase (day 8-day 12 of the cycle) for each patient.

\section{Statistical analysis}

Quantitative variables are expressed in terms of mean + SD and compared between groups using unpaired t-test and within groups across followups using paired t-test. Qualitative variables are expressed in terms of frequencies/percentage and compared using Fisher's exact test. The data were tabulated in MS Excel and analysis was performed using Statistical Package for the Social Science (SPSS) version 16.0 software.

Improvement in $\mathrm{Hb}$ and reduction in ET were compared in the pretreatment period in both the study groups. The $\mathrm{p}$ value was considered statistically significant if $<0.05$.

\section{RESULTS}

\section{Demographic characteristics}

All subjects were of Indian origin from New Delhi, India. The mean ages were 40.56 and 39.76 for ORM and norethisterone study groups, respectively.

\section{Mean $\mathrm{Hb}$}

The $\mathrm{Hb}$ levels were measured in both the study groups at regular intervals of time during the 3 -months.

ET

The ET of the two study groups was measured at regular intervals.

\section{Treatment outcomes}

Ormeloxifine is more superior and effective than norethisterone and can be considered as the first line of treatment.

\section{Effectiveness}

Ormeloxifine was found to be more effective than norethisterone.

\section{Safety}

Ormeloxifine is safer than norethisterone.

\section{DISCUSSION}

This study was conducted in Mata Chanan Devi Hospital, New Delhi, India. One hundred patients were enrolled in this study. The patients were divided into two groups - 50 patients were enrolled in Group A who accepted ORM treatment and the rest 50 patients were enrolled in Group B who accepted norethisterone treatment. The mean age of the population was 40.56 years in ORM and 39.76 years in norethisterone group. The majority of women were multiparous. Socioeconomic status was found to be relatively higher in ORM group, but the difference was not statistically significant $(\mathrm{p}=0.055)$. Hence, both the groups were matched in age, parity, and socioeconomic status. Mean duration of symptoms was similar in both groups, that is, 25.32 months and 27.24 months in ORM and norethisterone groups, respectively. It was higher in norethisterone group, but the difference was not statistically significant $(\mathrm{p}=0.306)$. Mean $\mathrm{Hb}$ at the time of presentation was $8.85 \mathrm{~g} \%$ and $8.75 \mathrm{~g} \%$ in ORM and norethisterone groups, respectively. Mean presenting $\mathrm{Hb}$ levels were comparable in both groups. Mean ET at the time of presentation was similar in both groups, that is, $11.94 \mathrm{~mm}$ and $11.83 \mathrm{~mm}$ in ORM and

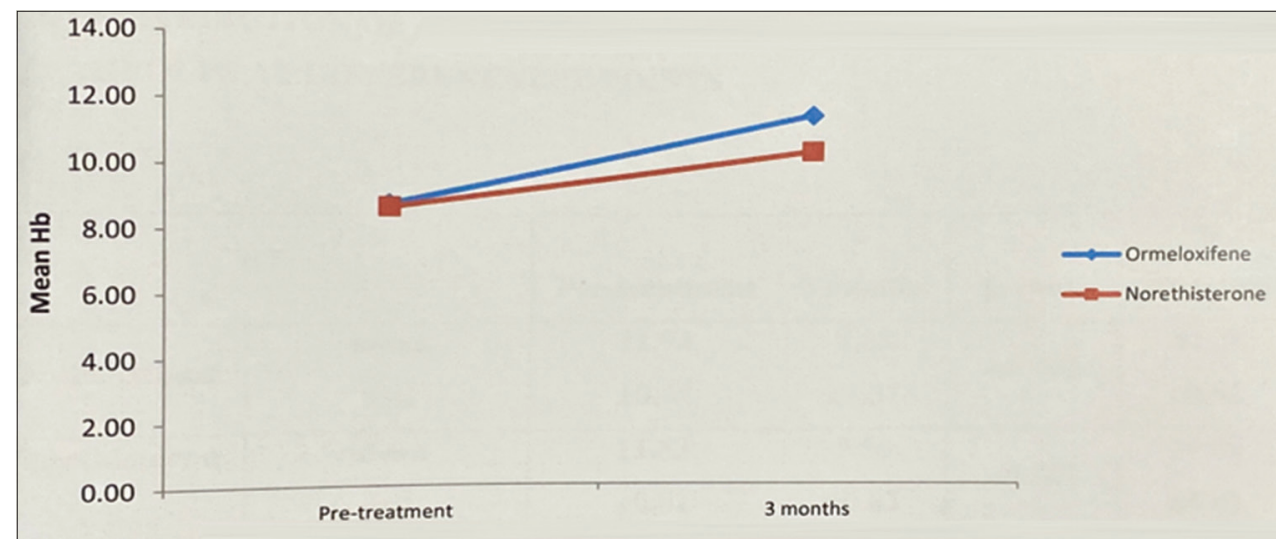

Graph 1: Comparison of mean hemoglobin (g\%) between study groups over 3 months

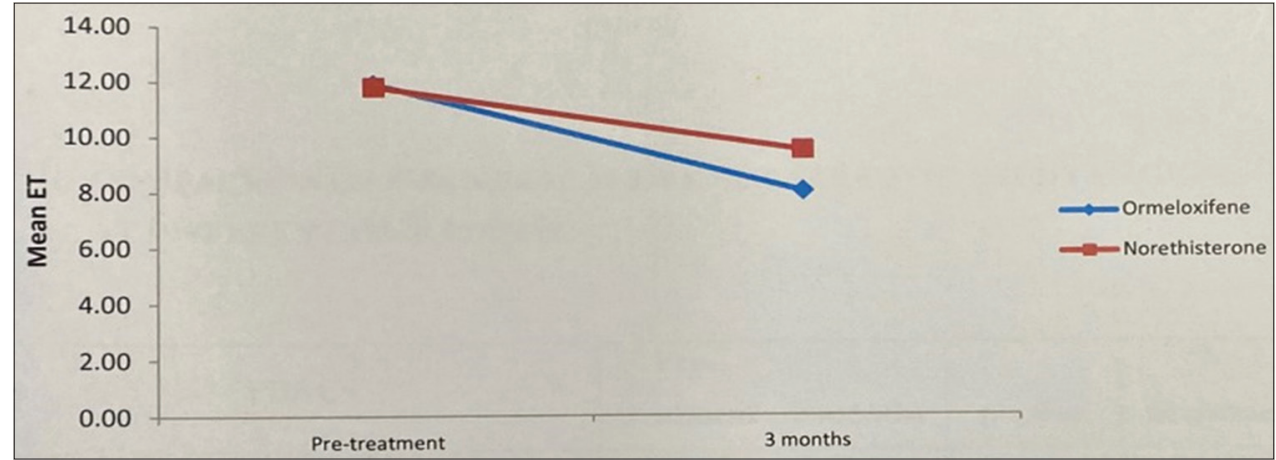

Graph 2: Comparison of endometrial thickness between the two study groups over 3 months 
Table 1: Mean age, parity, and duration of symptoms

\begin{tabular}{lllll}
\hline & ORM & & Norethisterone & p-value \\
\cline { 2 - 2 } & Mean \pm SD & & Mean \pm SD & \\
\hline Age (years) & $40.56 \pm 3.83$ & & $39.76 \pm 3.65$ & 0.144 \\
Parity & $2.46 \pm 0.81$ & $2.30 \pm 0.54$ & 0.125 \\
Duration of & $25.32 \pm 18.75$ & $27.24 \pm 19.02$ & 0.306 \\
symptoms (months) & & & \\
\hline ORM: Ormeloxifene & & &
\end{tabular}

ORM: Ormeloxifene

Table 2: Comparison of mean $\mathrm{Hb}(\mathrm{g} \%)$ between study groups

\begin{tabular}{lllll}
\hline Hb & Pre-treatment & 3 months & p-value & \% Increase \\
\hline ORM & & & & \\
Mean \pm SD & $8.85 \pm 0.8$ & $11.68 \pm 0.83$ & $<0.001$ & $32.40 \pm 6.28$ \\
Norethisterone & & & \\
Mean \pm SD $8.75<0.69$ & $10.54<0.74$ & $<0.001$ & $20.80 \pm 7.1$ \\
p-value (O & 0.257 & $<0.001$ & & $<0.001$ \\
versus N) & & & \\
\hline Hb: Hemoglobin, ORM: Ormeloxifene
\end{tabular}

Table 3: Distribution of ET between the two study groups over 3 months

\begin{tabular}{|c|c|c|c|c|}
\hline ET & Pre-treatment & 3 months & p-value & \% Decrease \\
\hline \multicolumn{5}{|l|}{ ORM } \\
\hline Mean $\pm S D$ & $11.94 \pm 0.94$ & $8.08 \pm 1.31$ & $<0.001$ & $32.36 \pm 9.92$ \\
\hline \multicolumn{5}{|c|}{ Norethisterone } \\
\hline Mean \pm SD & $11.83 \pm 0.81$ & $9.56 \pm 0.65$ & $<0.001$ & $19.09 \pm 4.41$ \\
\hline $\begin{array}{l}\text { p-value (0 } \\
\text { versus } N)\end{array}$ & 0.261 & $<0.001$ & & $<0.001$ \\
\hline
\end{tabular}

ET: Endometrial thickness, ORM: Ormeloxifene

norethisterone groups, respectively. ORM has been shown to be an effective and safe therapeutic option for the medical management of AUB. Chawla et al. [2], in their 2017 study, showed that use of centchroman (ORM) in conservative management of menorrhagia in premenopausal age group resulted in an increase of $\mathrm{Hb}$ level at the end of the study. Karmakar and Deshpande [3], in 2016, had done a study of efficacy and safety of ORM in a new treatment for DUB and the result was similar to our study. Jacob and Mini, [4] in their study in 2015, did a comparative study of both the drugs. Their result concluded that ORM is more effective than norethisterone in the reduction of ET and rise in $\mathrm{Hb}$. This, too, is similar to our study.

Bhattacharyya and Anusyua [5], in their 2010 study, evaluated the efficacy of SERM, that is, ORM in the management of AUB. The results of the study showed that there was a marked relief of symptoms with a significant reduction of blood clots and rise in Hb. Hence, the study concluded that ORM is superior to norethisterone and may be prescribed as a first-line treatment in the woman who has completed childbearing. This was similar to the conclusion of our study. Agarwal et al. [6], in 2019, had done a similar study on the efficacy of ORM and norethisterone in the management of perimenopausal DUB. The result showed that ORM is more effective than norethisterone in reducing blood loss, improving $\mathrm{Hb}$, and reducing ET in DUB. The results of this study are consistent with the results of our study.

Furthermore, a 2018 study by Devi and Nimonkar [7] showed that there was a statistically significant increase in $\mathrm{Hb}$ and statistically significant decrease in ET with ORM. They, therefore, concluded that ORM is safe, cost-effective, non-steroidal, and non-hormonal drug with convenient doses and better compliance, which is similar to our study. It was found to be an excellent drug in controlling the system of AUB without affecting the normal endocrinal and physiological parameters as a result that was similar to our study. Ravibabu et al. [8], in their 2013 study, showed that ORM was effective in reducing menstrual blood loss in patients in the treatment of AUB in all age groups with effective therapeutic efficacy and least side effects. They also concluded that the compliance of patients is good because of the convenient dosage schedule and no need of taking the drug every day.

\section{CONCLUSION}

AUB is the diagnosis in the majority of cases of HMB and accounts for a significant proportion of referrals to gynecologists. Both ORM and norethisterone can be good alternatives to the medical and surgical treatment of HMB with good efficacy.

There was an improvement in mean $\mathrm{Hb}$ in both the groups in this study, ORM being more effective as compared to norethisterone. Mean $\mathrm{Hb}$ at baseline and $3^{\text {rd }}$ month of treatment was found to be $8.85 \%$ and $11.68 \mathrm{~g} \%$, respectively, with ORM and $8.75 \%$ and $10.54 \%$, respectively, with norethisterone. Improvement in $\mathrm{Hb}$ was statistically significant in both groups $(\mathrm{p}<0.001)$.

In addition, ORM is superior to norethisterone in its ability to reduce ET. There was a statistically significant reduction in mean ET with ORM (from $11.94 \mathrm{~mm}$ down to $8.08 \mathrm{~mm}$ ) $(\mathrm{p}<0.001)$ and norethisterone (from $11.83 \mathrm{~mm}$ down to $9.56 \mathrm{~mm}$ ).

For a treatment course of 3 months, ORM was found to be more costeffective.

As both ORM and norethisterone are very effective in reducing blood loss, they can be considered as first-line drugs in the management of AUB-O. Both are conservative modes of treatment and help to reduce the rate of hysterectomy and morbidity and associated mortality.

\section{AUTHORS' CONTRIBUTIONS}

Dr. Jasleen Kaur, Consultant, Department of Obstetrics and Gynecology, $\mathrm{MCDH}, \mathrm{New}$ Delhi, provided guidance in the preparation of the manuscript and reviewed it.

\section{AUTHORS' FUNDING}

The study was funded by the Department of Obstetrics and Gynecology Outpatient of Mata Chanan Devi Hospital, Janakpuri, New Delhi.

\section{CONFLICTS OF INTEREST}

The author declares no conflicts of interest

\section{REFERENCES}

1. Munro MG, Critchley HO, Fraser IS, Haththotuwa R, Kriplani A, Bahamondes L, et al., FIGO Menstrual Disorders Committee. The two FIGO systems for normal and abnormal uterine bleeding symptoms and classification of causes of abnormal uterine bleeding in the reproductive years: 2018 revisions. Int J Gynecol Obstetr 2018;143:393-408.

2. Chawla SK, Bucha A, Sethi A, Puar NS, Paliwal V. Use of centchroman (saheli) in conservative management of menorrhagia: Our experience. Indian J Obstetr Gynecol Res 2017;4:220-4.

3. Karmakar S, Deshpande H. Ormeloxifene-a new treatment modality in dysfunctional uterine bleeding: Efficacy and safety. Indian J Obstetr Gynecol Res 2016;3:225-8.

4. Jacob KJ, Mini DA. A comparative study on the effectiveness of ormeloxifene versus norethisterone in the management of perimenopausal dysfunctional uterine bleeding. Int Arch Integr Med 2015;2:87-92.

5. Bhattacharyya TK, Anusyua B. Efficacy of a selective estrogen receptor modulator: Ormeloxifene in management of dysfunctional uterine bleeding. J South Asian Fed Obstetr Gynaecol 2010;2:207-11.

6. Agrawal P, ShindeU, Shinde S, Aher G. Efficacy of ormeloxifene vs norethisterone in the management of perimenopausal DUB. VIMSHSJ 2019;6:30-3.

7. Devi LT, Nimonkar R. Ormeloxifene in the management of dysfunctional uterine bleeding. Int $\mathrm{J}$ Reprod Contracept Obstetr Gynecol 2018;7:1886.

8. Ravibabu K, Palla J, Chintada GS. A study of efficacy of ormeloxifene in the pharmacological management of dysfunctional uterine bleeding. J Clin Diagn Res 2013;7:2534. 